VIII.1, Winter 1986

Informal Logic

\title{
Is Critical Thinking a Technique, Or a Means of Enlightenment?
}

\author{
LENORE LANGSDORF University of Texas at Arlington
}

\section{Introduction}

This paper proposes a theoretical basis for practicing and teaching critical thinking as both "technique" and "means for enlightenment." Since the current state of the art (as reflected in journal articles as well as textbooks) seems to me more advanced in developing techniques, the stress here is on "enlightenment." Thus, the ideas I explore are offered as a contribution on the "basic theoretical underpinnings" which Richard Paul recognizes are needed for "critical thinking in the 'strong' sense." [1] This is to say that I will be proposing a theoretical basis for understanding that conception of critical thinking as a means for enlightenment. In order to do so, I will offer some thoughts on what enlightenment might be, why certain features in our cultural history have resulted in its atrophy, and how we might make a start toward changing that situation.

The paper has three parts. Part One presents the notion of "instrumental reason" as a mode of reasoning quite different from "judgment." The former is concerned with developing techniques for achieving alreadystipulated ends by utilizing alreadygiven means. The latter is concerned with an extended sense of reasoning which examines those means and ends in the light of human needs and goals. In presenting this concept, l'll be relying on the work of lan Angus, which is situated at the juncture of phenomenology (as developed by Edmund Husserl) and the Critical Theory de- veloped by the Frankfurt School.[2] The inadequacies of "instrumental reason" and the prospects of "judgment" seem to me illustrated in Richard Paul's critique of any teaching of critical thinking that would be the mere application of techniques, rather than the cultivation of a "dialectical mode of analysis."

What I'm doing in Part One, then, is associating Angus's "instrumental reason" with Paul's "critical thinking in the 'weak' sense," and Angus's "judgment" with Paul's "critical thinking in the 'strong' sense." I hope that relating Paul's proposals to the phenomenological and Frankfurt School traditions in this way provides us with the beginnings of a theoretical basis for "strong sense" critical thinking.

In Part Two, I consider a question that seems to me comparatively neglected in Paul's work: why is it so difficult to reach the non-egocentric standpoint that is the starting point for the "dialectical mode of analysis" he advocates? Here and in Part Three, I rely on Paul Ricoeur's conception of "ego" as contrasted with "self" in proposing that we might be more successful in cultivating a non-egocentric standpoint if we have some understanding of egocentricity as an inevitable, but transcendable, starting point.[3] In Part Two, then, I suggest that an insistently pervasive technology-television-suppresses a capacity-imagination-that is crucial to any attempt to move beyond "ego" to "self." A form-and-content distinction is crucial to this suggestion: if the 
portrayal given here is accurate, suppression of imagination occurs by virtue of television's very form, not only or even primarily because of its programming content.

In Part Three, I propose that another technology-the printed word, which does not share television's formstimulates rather than suppresses imagination. Ricoeur's thesis that "ego" becomes "self" through involvement with "text," I suggest, provides "theoretical underpinnings" for a critical thinking that responds to Paul's critique, as well as to Angus's call for an undoing of the "reversal of enlightenment" brought about by universalized instrumental reason.

\section{Part One:}

\section{Instrumental Reason and Judgment}

The expansion of techniques which is legitimized by instrumental reason turns the objects of the life-world into mere residues... while it reduces the subject to an untheorized plurality of ends-instrumental reason results in world alienation and self-alienation. This systematic crisis involves a new situation for philosophy. [4]

I take it to be self-evident that virtually all teachers of critical thinking want their teaching to have a global 'Socratic' effect, making some significant inroads into the everyday reasoning of the student, enhancing to some degree that healthy, practical, and skilled skepticism one naturally and rightly associates with the rational person. [5]

In this section, I propose that the prevalence of "instrumental reason," as identified in Ian Angus's critique, is one of the powerfui factors in our culture which work against our efforts at having, in our teaching of critical thinking, the "global 'Socratic' effect" on our students that Richard Paul identifies. This is to say that our students come equipped with instrumental reason, since it is endemic to our culture, and that this form of reason is inimical to critical thinking

Angus's critique identifies instrumental reason as the type of reasoning which is limited to determining appropriate means for achieving a particular end. What it does not do is consider the appropriateness of either means or ends to larger contexts, such as an individual's or society's everyday or major life-decisions.[6] His term for the type of reasoning that would take up that larger-indeed, "global"task is "judgment." In exploring both these conceptions of reasoning, Angus is expanding upon work on the nature of reason done from the perspective of the Critical Theory developed by the Frankfurt School, in that he adds the "self-reflective and critical character of phenomenology," and in particular, Husserl's emphasis upon the "constitution of theoretical objectivities" (such as the elements of a logical system), in order to develop a theoretical basis that would enable us to "renew the promise of enlightenment." [7]

This renewal is needed, according to Angus's account, because of an historical paradox: the science and technology which earlier philosophers and scientists expected would liberate humanity from the arbitrariness and harshness of nature, now appear to many as replacements for the domination practiced prior to the rise of science in the Enlightenment by the "mythicoreligious tradition." [8] This has occurred, he argues, as the science developed by Bacon, Descartes, and Galileo required a "transformation from the Classical question 'why' things are to the modern 'how'."[9] Angus retains both questions within his own analysis, although my focus here is on just one: how does this "reversal of enlightenment" occur?[10] For considering Angus's analysis together with Paul's suggests that the critical thinking courses which many philosophy departments now find are their most popular offerings are training students in instrumental reason (at most), rather than cultivating that "Socratic" and "global" form of reasoning which Angus calls judgment.

We are teaching instrumental reason rather than judgment, I suggest, insofar as we use what Paul calls the 
"standard modes of teaching critical thinking," based on "a fundamental and questionable assumption": that it can be taught as a "battery of technical skills" to be "mastered" and applied (as means to an end) without asking any "why" questions concerning the context in which the student (subject) or issue (object) is embedded.[11] On this model, Paul goes on to say, arguments are encountered "atomically," rather than as "networks" delineating "world views." In effect, what we are doing in this mode of teaching critical thinking is taking the student, who comes to us more-or-less well equipped by our culture with instrumental reason, and working to instill techniques which exercise that equipment.

Paul calls this "critical thinking in the 'weak' sense," and gives us a succinct summary of its usual results. One likelihood is " sophistry" ": the student "learns to use technical concepts and techniques to maintain his most deep-seated prejudices and irrational habits of thought." The alternative is " 'dismissal' "-outright rejection of rational modes of thought "in favor of some suggested alternative-'feeling,' 'intuition,' 'faith,' or 'higher consciousness.' "[12] Both of these are a long way from the goals of teaching critical thinking that are cited at the start of this section, and there are a variety of responses we can give to this disjuncture between goals and results. I will sketch Angus's response, and then Paul's, and then suggest two inadequacies in the latter which may be remedied by incorporating elements of the former.

Angus finds that instrumental reason's restriction to the application of given means-such as logical systems - to given ends is a contribution to what Husserl called "the crisis of Western humanity [which] rests on a conception of reason in which formalization held sway such that the genuine advances by special sciences and formal logic are severed from philosophical enlightenment." [13] Husserl's own response to that situation was to show that formalizations derive from (in his words, are "founded in") material conditions (in his words, again, the "lifeworld").[14]

This phenomenological description of the relation between intellectual and everyday life (e.g., logic and the lifeworld) is incorporated into Angus's theory of "judgment" when he argues that using logical structures in a normative manner within the whole of our experience does not depend upon any "cosmological intuition," or transcendent "organizing principle," or "traditional authority" of the sort associated with "mythico-religious worldviews" which have been rather discredited, since the onset of the Age of Science, as sources of epistemological justification or ontological validation.[15] Rather, the justification for using logic normatively has its source in evidence that results from a phenomenological analysis of the lifeworld:

\begin{abstract}
Husserl's transcendental logic sets itself the task of delineating the range and legitimate objects of traditional logic through a regressive analysis into the 'sense' of the formalizing abstraction that is at its [logic's] root, and teleological inquiry into the 'truth' with which formalizing abstractions can judge about individuals. [16]
\end{abstract}

For Angus as well as Husserl, the "'sense' " found in this regressive analysis is that the formal is manifest, as inherent modes of structure and order, in the material. In other words: Husserl's work on logic and the lifeworld shows that the latter displays the former; that the form of our reasoning is implicit in that content. Thus, his "redirection of philosophy [which] take[s] the whole of the experienced lifeworld into thought" is a redescription of practice as always already informed by theory. [17]

If we accept Husserl's demonstration that "formalism is not self-enclosed, but rests on presuppositions of sense and teleology of truth in the lifeworld," we need not accept the "reduction of human action to technique."'[18] Angus takes Husserl's demonstration of logic as embedded 
within experience as the basis for his claim that insofar as logic is justifiably (rather than arbitrarily or dogmatically) applicable to theorizing in general, we are justified in extending our reasoning beyond the limitations of instrumental reason; he calls this expanded conception "judgment." He goes on to develop this broader notion of reasoning as including rational consideration of the contexts from which issues and arguments arise, and to which techniques apply.

Identifying contextualized objects as the recipients of technical action implies two further differences between instrumental reason and judgment. First, ends can now be thematized as distinct from, and perhaps problematically related to, objects. Also: judgment, in reflecting upon objects within their contexts, discovers that "it is the context from which technical ends stand out that establishes the possibility of a plurality of ends" which are "formulated from" their contexts and "cannot be conceived as existing prior to the formation process." [19]

Reasoning, understood as judgment, is thus revealed as an activity with two instrinsic and usually unnoticed dimensions. It thematizes objects in the lifeworld as presentations of a particular individual's "immediate experience," and it thematizes them also as representations, informed by theory. In other words, this conception of reasoning understands our reasoning as intrinsically incorporating both presupposed logical systems (formalization) and means-ends correlations which are supplied by cultural and individual goals, needs and valueswhich is to say that they are inevitably egocentric and sociocentric. In contrast to instrumental reason, judgment thematizes those unnoticed presuppositions within its own activity, as well as reasoning about the objects which are instrumental reason's sole interest. In Angus's words,

Both sides of this theory/life-world relationship are involved in judgment. In order to overcome the crisis of reason judgment must be both representative and presentational.... The tradition of thought cannot be taken to be exhaustive; we must return to the generating experiences from which thought emerges. Judgment is an inter-relationship of immediacy and critique.... [20]

The contrast between instrumental reason and judgment deepens when we notice that judgment is intrinsically bound to a judging process, carried out by a judging self who is capable of actualizing a spectrum of possible perspectives on judged subject matter, and is also capable of reflecting upon that process. Cultivating or developing these capacities is then a force for undoing the "reversal of enlightenment" brought about by instrumental reason's limitation to formalizations, unconnected to the lifeworld, and technique, connected only to means-end deliberations.

A last, rather lengthy, quotation from Angus stresses the integration of self, process, object, and reflection in his notion of judgment, in a way that enables us to see the explicit connection between his proposal and Paul's:

\footnotetext{
Judgment makes the absent present.... The compatibility or contradictoriness of representations which are gathered from varying perspectives must be considered; what is at issue is not the accuracy of each one in isolation but the degree to which they can be combined into a comprehensive judgment. This involves a dual reflection: on the object as it emerges and...on the subject which must harmonize, or comprehend the dissonance of, representations....These considerations culminate in an individual judgment, a universalizing claim embedded in a singular statement about the public object. This claim can be contested-its journey around the object is not the only possible one.... Similarly...the entirety of the self... is open to constitution in judgment.... The constitution of self and world by judgments is never exhausted by existing judgments. It remains a particularization of an unlimited possibility of constituting judgments....Judgment is critrical thinking; it proceeds as critique...both inside and outside received representations. Actual judgments
} 
hand down the public realm, yet critical thought measures its limitations by incorporating new elements derived from the present and forming a new individual judgment.... There is no method for critique.... [it] does not proceed arbitrarily, but it cannot be fixed into a method.[21]

This reconception of our reasoning ability offers a theoretical basis for Richard Paul's "alternative view" of critical thinking.

The "'strong' sense" of critical thinking that Paul has been developing abandons atomic skills, arguments and issues in favor of comprehending any technique as only one among "a more complex set of actual or possible moves" which enable us to "organize or conceptualize the world, and our place in it, in somewhat different terms than others do." [22] Rather than remaining within the limitation of any actual argument or issue, then, Paul would relocate the reasoning process to a realm of possible personal and social world-views, actions, and judgments. He stresses that it is only when we (both students and teachers) come to recognize that any

given argument reflects, or if justified would serve, a given interest that we can, by imaginatively entertaining a competing interest, construct an opposing point of view and so an opposing argument or set of arguments. It is by developing both arguments dialectically that we come to recognize their strengths and weaknesses.[23]

"Arguments," as he goes on to say, "are not things-in-themselves"; rather, they are actual or possible presentations of factual or imagined contexts, from actual or imagined perspectives (world-views).

The example Paul provides of how to teach "critical thinking in the 'strong' sense" seems to me to respond, in some ways, to the need to move from the actual to the possible; from a "given" situation or argument to "imagined" alternatives. Two films which present radically different sets of "facts" in portraying one situationU.S. involvement in Central America- do provide a demonstration of Paul's recognition that "the media" typically present "a profoundly nationalistic bias," and that any " 'ego' is identified in part with the national 'ego."'[24] Exploration of that situation can be the first step toward recognizing that our usual means of reasoning -i.e., instrumental reason-do not go beyond the "given interest" represented in any "given argument." We can then go on to make that interest itself explicit, to "imaginatively construct" others, and to develop our considerations of these alternatives in a dialectical manner.

There are two aspects of the notion of judgment that are not paralleled in Paul's proposal, however. My suggestion that they be added is offered on the basis of agreeing with the problems and dangers (e.g. "sophistry" and "dismissal") he identifies, and so proposing additional "theoretical underpinning" for effective teaching of "critical thinking in the 'strong' sense."

The first aspect of judgment that I would add to Paul's procedure is suggested by the following remark, which occurs when he gives us "some basic theoretical underpinnings for a 'strong sense' approach":

Reasoning is an essential and defining operation presupposed by all human acts. To reason is to make use of elements in a logical system to generate conclusions.[25]

But if we do not inquire into what appears here to be the merely "given" character of "a logical system," we limit ourselves to the question of "how" (do I apply these "elements") and exclude the question of "why" (they should be applied). This allows a powerful feature of instrumental reason to remain within our reasoning

We need, therefore, to do some phenomenological analysis in order to discover just what logical elements are implicit in our reasoning. Although Husserl's analysis of formal systems can serve as a model for this activity, I suggest that actually carrying out this 
analysis in classroom practice is preferable for theoretical and pedagogical, as well as ethical, reasons. The theoretical and pedagogical advantages derive from our ability to justify the "use of elements of a logical system" on the basis of identifying them as intrinsic structures of actual argumentsrather than as independent, abstract rules which the critical thinking teacher prescribes in much the same way that the medical doctor prescribe drugs for an illness. The ethical aspect involves our ability to show why "elements in a logical system" should apply to our arguments and actions. For neglecting to justify our prescriptions places us in the rather paradoxical position of saying to our students: "If you want to be a critical thinker, do exactly as 1 say."

The second aspect of judgment which I would add to Paul's proposal is suggested by this mention of his own context:

I teach in the United States.... [T] media here as everywhere reflects, and the students have typically internalized, a profoundly 'nationalistic' bias.... [T] heir 'ego' is identified in part with the national 'ego,' nevertheless they are not...incapable of beginning the process of systematically questioning it. [26]

Despite the phrase "as everywhere" in this remark, Paul's proposal is often read as critical of our media in particular; and even, as claiming that American students and American culture in general are more nationalistic than others. This seems to me a misreading of his proposal which may be encouraged by a lack of explicit attention to the question of whether he is talking about reasoning in general, or as it is present in his particular situation. The principle of charity seems appropriate here, for the overall context of his work suggests that he is talking about the nature of reasoning itself, and how to cultivate improvements to it, rather than about any particular manifestation.

Presentation (as contrasted to representation) is the aspect of Angus's con- ception of judgment which would be helpful here in two ways. First, it provides us with a theoretical (i.e. ideal) point from which to recognize that the "constitution of self and world by judgment is never exhausted by existing judgments." [27] Exploring the evidence for this feature of judgment (as provided by our own biographies and in fiction) allows us to recognize that any world view is intrinsicallyby virtue of the very nature of human reasoning $-a$ "particularization [an actual instance] of an unlimited possibility of constituting judgments." [28] We can thereby avoid getting sidetracked into any implication that our own reasoning is being singled out as particularly or especially deficient; e.g., that the media in our society is especially biased, or that a particular individual has a psychological deficiency or social disadvantage which interferes with reasoning.

The second way in which the shift from a focus on individual cases to a concern with general structures is helpful involves understanding how it is that we can "internalize" bias without becoming "incapable of the process of systematically questioning." The feature of human being which allows this to occur, I suggest, is the theoretical reciprocity of perspectives which phenomenological analysis of the life world confirms. In practice, this is often limited; one way to understand what critical thinking teaching is about, I suggest, is as the cultivation of that capacity for reciprocity. Paul refers to this as the necessity of moving from an egocentric and sociocentric world view to a dialectical one, and notes that he is "beginning" on the "development of 'strong sense' approaches" to teaching critical thinking on the dialectical model.[29]

One of the "theoretical underpinnings" for those approaches (which also need development, I suggest) is the effect of the media on our capacity to move from the egocentric standpoints from which human beings inevitably begin. In the following two sections, then, I will consider the ways 
in which two of the media-television and the printed word-may influence our capacity for moving from egocentricity toward a more public-dialogical or dialectical-position in which we are more capable of "systematic questioning."

\section{Part Two: \\ Television and Imagination}

Critical thinking is possible only where the standpoints of all others are open to inspection. Hence, critical thinking while still a solitary business has not cut itself off from 'all others.'...[By] force of imagination, it makes the others present and thus moves potentially into a space which is public, open to all sides...To think with the enlarged mentality - that means you train your imagination to go visiting...[30]

If you decide to watch television, then there's no choice but to accept the stream of electronic images as it comes. The first effect of this is to create a passive mental attitude....Thinking only gets in the way. There is a second difficulty. Television information seems to be received more in the unconscious than the conscious regions of the mind.... The image doesn't exist in the world, and so cannot be observed as you would another person.... Perhaps this quality of nonexistence, at least in concrete worldly form, disqualifies this image information from being subject to conscious processes: thinking, discernment, analysis. [31]

My theme in this section can perhaps be best stated in hypothetical form: if, as Hannah Arendt claims, the "force of imagination" is crucial to moving us from egocentricity; and if, as Jerry Mander asserts, television as a techno$\log y-i . e$. in its very form, rather than by virtue of its contents (the programming)-suppresses our "power of forming a mental image of something not present to the senses or never before wholly perceived in reality" (which is a dictionary definition of "imagination"), then we have a situation in which the most pervasive technology in most of our lives, television, works against the capacities for "imagina- tion, discernment, [and] analysis" that are basic to thinking critically.

The "four arguments for the elimination of television" developed (albeit in a speculative and "nonscholarly" fashion) by Mander focus primarily on the "technology being used upon viewers" so that they-which is to say, we-can separate technique from content" and examine the

erroneous assumption that technologies are 'neutral.' We have not learned to think of technology as having ideology built into its very form.[32]

By virtue of its form, Mander argues, television is

less a communications or educational medium, as we wished to think of it, than an instrument that plants images - and does so in a way that allows for no cognition, no discernment, no notations upon the experience one is having.[33]

Before going on to consider Mander's claims, I want to discuss the role that imagination plays in Angus's and Paul's critiques. We can then consider Mander's claim that the form of television-television by virtue of its very technology-suppresses the development of imagination, and thus, suppresses our capacity to "go visiting" beyond egocentricity; i.e., exercise judgment in that "public space" where dialogical thinking occurs. [34]

In the course of discussing Hannah Arendt's remarks on imagination (quoted at the start of this section), Ian Angus indicates how imagination expands judgment beyond the limits of instrumental reason:

The operation of representation is a function of the imagination in which the 'free play' of the mind is not limited by a definite concept. Kant describes the imagination as 'gathering together the manifold of intuition': it is not limited to actual presentations but consists in the combination and re-arrangement of previous, present, and anticipated presentations. This imaginative reconstruction does not take place with reference to a pre-defined purpose but rather involves a relationship to an anticipated singular judgment of a parti- 
cular which itself implies a universalization.[35]

There are three ways that imagination functions, then, which makes it essential to judgment: it "gathers" the contributions of our different senses; it gives us access to presentations that are actually absent, but potentiallyas "anticipated" - present; and it enables us to transcend "reference" (delimited, "pre-defined" ends) by anticipating alternative possibilities. If we consider how the mind would function without these abilities, we have a close approximation to Angus's characterization of instrumental reason that limits us to actual techniques for means-end deliberation.

Richard Paul's discussion of the differences between critical thinking in the "strong"' and "weak" senses suggests that these same three functions of imagination are necessary if the ego is to move beyond "atomic arguments" that are presented without any concern for context-i.e. either the individual subjects or the specific situations which give rise to those arguments. "Strong sense critical thinking" recognizes that these arguments "are in fact a limited set of moves within a more complex set of actual or possible moves reflecting a variety of logically significant engagements in the world. "[36] Since we can only evaluate the "strengths and weaknesses of the [particular case of] reasoning in relation to alternate possibilities, "critical thinking in the 'strong' sense" simply cannot be practiced within the limits of actual egocentric and sociocentric positions:

It is only when we recognize...that a given argument reflects...a given interest that we can, by imaginatively entertaining a competing interest, construct an opposing point of view ....[37]

Paul's "sample assignment" certainly uses the imagination in this way. For it is designed to go beyond the ego's all-too-comfortable starting point and resting place, by requiring the student to "view and analyze critically...two incompatible world views" and then "construct a dialogue between two of the most intelligent defenders of each of the points of view."'[38] Rather than apply a technique to an actual argument, the student must generate and reflect upon possible arguments in a dialogical manner, and so transcend the egocentric world view from which we all begin to reason.

However, the technology of television, as Mander portrays it, is one which encourages the ego to develop quite an opposite set of reactions. "Instead of training active attention," one of the researchers he cites says, "television seems to suppress it." [39] Instead of requiring the ego to use its experience and imagination to transcend egocentricity, this technology requires the ego to stay put-quite literally, as well as figuratively.

In contrast to imagination's function in "gathering" the contributions of all five senses, television engages only two, and even these are often sundered in a way quite alien to the presentations of pre-technological life. For example: the visual and aural stimuli are often non-synchronized, as when we see people walking on a distant hillside but hear their conversation as though they were next to us.

The natural informational balance between aural and visual has been shattered. Now, information that you take in with visual sense cannot be used to modify or help process the information from the aural sense because they have been isolated from each other and reconstructed.[40]

This "isolation" and "reconstruction," moreover, are not a product of our own imagination, and so the process which accomplished them is not available to our reflection. If it were, we might train our imagination to thematize other ways in which it might have been done; other products which might have resulted. Instead, we have a hidden process, instigated by an unknown author, and resulting in a product quite isolated from our own actual lived experience. The "two semioperative senses cannot benefit from the usual mix of information that 
human beings employ to deduce meaning from their surroundings." [41] The ego is instead reinforced in its isolation, supplied with "implanted images," all of which "arrive in sequence with equal validity." [42] It has passively received the product of a "process of...dissociation and restructuring... which automatically confines reality to itself." [43]

What this isolated ego has not done is interact, both actually and imaginatively, with pretechnologically-processed lived experience-which is the real context of both logic and logicusers. In that interaction (and in situations such as Paul's sample assignment) the ego has opportunities to choose and develop alternative possibilities, and then, to discover and develop logical practices in order to judge competing claims to validity. "Knowledge is gained," as Mander points out, "by discerning change, by noting the event that is different from all others, by making distinctions and establishing patterns." [44] Our everyday lived experience provides opportunities for these activities, but they are absent in the processed experience (so to speak) provided by television.

Although I have limited this consideration of television to the effect of its form upon the development of imagination, and thus on the cultivation of our capacity to become critical thinkers, one remark by Mander about content is so directly relevant to critical thinking as to demand inclusion. In a study reporting on what sorts of knowledge viewers believe they gain from television programs, "practical knowledge and methods of problem-solving lead the list of knowledge reported acquired through these program." [45]

Regardless of programming content, however, the very form of television deprives the ego of the conditions for attaining knowledge which are offered by actual and imagined experience. Nor will additional technology-e.g. recorders which allow us to replay fleeting images, or pause when we wish to reflect on them-repair this lack. For we have no part in the supply and mix of its perspectives, no contribution to the internal temporal structure of the finished product, and no ability to supplement it with alternative images of the same kind.

My consideration of television as a form has focused on its technology as one which intrinsically suppresses the conditions needed for an ego to develop the "imaginative force" needed to relocate from egocentricity to that dialogical "space" identified by Hannah Arendt as "public, open to all sides."[46] This should not be construed as any sort of generalized rejection of technology, or even as agreement with Mander's assertion that television should be "eliminated." Rather my interest in the effects of cultural factors on reasoning capacity is instigated by the conviction that our attempts to teach "strong sense" critical thinking stand a better chance of surviving those "moments of frustration and cynicism" that Paul mentions if we are aware of factors in the culture which operate at cross purposes to ours.[47] Correlatively, I believe that we are more apt to teach "strong sense" critical thinking effectively if we make use of factors in our culture which support the development of imagination, and thus, aid in cultivating our capacity to be critical thinkers. If Paul Ricoeur's thesis is correct, another technology-the printed word-provides such aid. We can now consider his proposal: the ego becomes the self-i.e., transcends its egocentricity - through encounter with text.

\section{Part Three: Ego, Text, and Self}

fiction is not an instance of reproductive imagination, but of productive imagination....all symbolic systems have a cognitive value: they make reality appear in such and such a way...they generate new grids for reading experience or for producing it.[48]

appropriation is the process by which the revelation of new modes of being... gives the subject new capacities for knowing himself.... Thus appropriation 
ceases to appear as a new kind of possession....It implies instead a moment of dispossession of the narcissistic ego..... should like to contrast the self which emerges from the understanding of the text to the ego which claims to precede this understanding. It is the text, with its universal power of unveiling, which gives a self to the ego.[49]

My theme in this concluding section is that at this point in human history, the ability to think critically, as nonegocentric selves, is dependent upon the encounter with texts that portray an imagined world-i.e., with literary texts.

A crucial distinction must be stressed at the outset. Just as the previous section proposed that the form of television suppresses imagination, and thus opposes the very possibility of critical thinking, my argument here is that the form of literary texts supports, and perhaps even fosters, the development of imagination and (therefore) critical thinking. Since this claim is directly dependent upon Paul Ricoeur's theory of text, I offer a summary of that theory, and conclude with a brief mention of one endeavor to teach critical thinking from the theoretical basis I propose here, and which derives from his work. Before considering Ricoeur's work, however, I begin with Mander's remarks on the technology of text, in contrast to television.

The persistent theme in Mander's critique of television as a technology is that its very form "implants images" that rule out depth, subtlety, and comparison with actual experience, and it does this all in a manner that "dissociates" and "restructures" those images. Thus, he argues, "discerning" their variation from sequences in the lifeworld, "making distinctions" among them, or "establishing patterns" that transfer reliably to the lifeworld which they purport to represent -in short, all of the acitivies which critical thinking seeks to develop-are discouraged. Instead, "passive" reception of these technologically produced images is encouraged.[50]
One reason for discounting Mander's portrayal, I suspect, is our recognition that all of our experience is "artificially reconstructed" by technology. Mander holds that our only choice is between "accepting this interpretation of reality as our own" and rejecting it in favor of "trying to understand the world solely through [our] own isolated mental processes." [51] A third alternative, however, would be to seek, within our technologically formed environment, means that provide some assistance in transcending our sociocentric and egocentric context. Mander does note that the printed word, by virtue of its form, offers that possibility:

print can express much greater depth, complexity, change of mood, subtlety, detail....Books...can be written in much slower rhythms, encouraging a perception that builds, state by stage, over the length of a long reading process....[52]

As one of Mander's sources noted: "The response to print may be fairly described as active... while the response to television may be fairly described as passive." [53]

Ricoeur's analysis of "response" as the "appropriation" moment of our interaction with printed discoursetext-identifies it as a culminating moment that displaces "narcissistic ego" in favor of an emerging "self." Both the author's and the reader's egos are transcended in this moment:

The relation to the world of the text takes the place of the relation to the subjectivity of the author, and at the same time the problem of the subjectivity of the reader is displaced. To understand is not to project oneself onto the text but to expose oneself to it; it is to receive a self enlarged by the appropriation of proposed worlds which interpretation unfolds. ...fiction is... a fundamental dimension of the subjectivity of the reader: in reading, I 'unrealize myself.' Reading introduces me to imaginative variations of the ego.[54]

In the public space of the proposed (i.e., possible or potential) world "in front of the text," then, we have "a recourse against any given reality 
and thereby the possibility of a critique of the real." [55] To interact with the possible world of the text is to enlarge "reality" by including "ideality"i.e., possibilities that transcend time, or are omni-temporally available. When the ego encounters text, then, there is a displacement from a given, actually existing egocentric situation, to a domain of meaning which is always potentially available to anyone who takes up the text, reads, and may thereby become enlightened. [56]

Appropriation of the text's meanings is a process that contrasts quite dramatically to reception of television's images (as in Mander's account), or projection of the ego's world view (as in Paul's portrayal), or assimilation of the culture's values (as in Angus's critique). In Ricoeur's analysis of the nature of our interaction with text, "appropriation is the dialectical counterpart of distanciation," which is, in turn, "the condition of possibility of understanding oneself in front of the text."[57] This latter feature of the form of text is unique in our present historical situation: neither television's images nor our culture's values are distanciated; i.e. they do not appear to us as objects that are alien to us as subjects. In the case of television, they quite literally come to be within our perceptual processes: "the image doesn't exist in the world. "[58] In the case of cultural values, they are incorporated into ends that are assumed (by instrumental reason) to lie outside of reason's proper sphere.

The evidence for Ricoeur's dialectic of appropriation and distanciation is phenomenological: i.e., it is derived from his observations of lived experience. Distanciation as an essential feature (moment) of the reader's encounter with text is documented quite vividly in reports by poetry and literature teachers. They despair, at least at times, of making the content of the "great books" accessible to their students. In terms of Ricoeur's analysis: the spatiotemporal distance between the world of those texts and the situations of contemporary students is such that appropriation of the text's world appears to be impossible. Students insist that requiring them to defend their interpretations amounts to denying those "feelings," "intuitions," and "higher consciousness" mentioned by Paul as common alternatives to critical thinking. Or, they refuse to encounter the texts on any level past that of plot synopsis, and that only for purposes of passing an examination. Accepting either result, if we continue to use Paul's terms, would be teaching literature in a "weak sense"; i.e. as an aid to "sophistry" or incentive for "dismissal" - despite the teacher's hope that a "global 'Socratic' effect" (even, enlightenment) would occur.

Ricoeur proposes that distanciation, as a moment (essential feature) of the form of text, determines that distance of content evidenced by this classroom experience. Both types of distancing can now be understood positively, as part of the "condition of possibility of understanding" both self and world.[59] We have already looked at the nature of appropriation in that way; a correlative look at the nature of distanciation will enable us to focus on a common feature in both moments and-by means of that feature-on the value of literary texts for teaching critical thinking.

Distanciation is Ricoeur's term for the text's presence as a perennially distant and autonomous force-an "atemporal object" that solicits temporal responses.[60] This is not the sort of object that can be possessed; $\mathrm{Ri}$ coeur specifically warns us that "appropriation" is not "a new kind of possession."[61] The atemporality of the text-also called omni-temporality and ideality-reinforces its character as alien to us. It has an essentially distant nature which

\footnotetext{
is the ruin of the ego's pretension to constitute itself as ultimate origin. The ego must assume for itself the 'imaginative variations' by which it could respond to the 'imaginative variations' on reality that literature and poetry, more than any other form of discourse, engender.[62]
} 
In other words: faced with an object that presents alternatives to the "false evidences of everyday reality" -especially its implicit claim to be the only possible reality - the reader is pushed to respond to the force of the text from a standpoint other than that reader's everyday reality; i.e. from a standpoint that remains centered upon, but is no longer limited to, the actual ego. [63]

Given the mode of inquiry inculcated by our "scientific age" (operating with instrumental reason), the inevitable question that greets this analysis is: "how"? Ricoeur's response is to direct us towards a capacity, rather than to impose a method (technique):

\begin{abstract}
Are we not ready to recognize in the power of imagination, no longer the faculty for deriving 'images' from our sensory experience, but the capacity for letting new worlds shape our understanding of ourselves? This power would not be conveyed by images, but by the emergent meanings in our language.[64]
\end{abstract}

The less-asked question, and the one which moves us beyond instrumental reason, is: "why"? Paul's and Angus's critiques suggest the teleological response to that question: the goal of encountering text is that "global 'Socratic' effect" called "enlightenment."

The power of the text resides, then, in ideal (omni-temporal) meanings which originate beyond the real (temporally restricted) situation of the reader. Actualizing or realizing those meanings requires exercise of the "power of imagination," if they are to have significance within the reader's particular situation.[65] Correlatively, readers "unrealize" (so to speak) those particular meanings in their encounter with the text's meanings. Through this process, the egocentricity of both reader and author are transcended.[66] The "ego divests itself of itself," freeing the reader for relocation "beyond the limited horizon of his own existential situation." [67] And this is precisely where he needs to be,
Richard Paul argues, if "critical thinking in the 'strong' sense" is to occur.

Not coincidentally, the college within which I teach is developing a conception of teaching literature, critical thinking, and writing in an integrated manner, so that our students (and we ourselves) can reflect upon our egocentric situations from within the public space - the world-constituted by the text.[68] We would like to reverse the culturally-implanted presupposition that books, logic, and composition are things that have a quasiexistence in the classroom, at best.

Our hypothesis is that the way to accomplish that reversal is to thematize the origins of these "things" in, and their applicability to, the lifeworld of readers, writers, and thinkers. The aim is to integrate philosophy, literature and composition within the context of the students' lives, rather than present them as abstract entities to be applied as techniques or seen as conducive to some form of "higher consciousness" - and thus limited to an inner, egological situation. The multiplicity of interpretations arising from reading texts can be used, in that integrated context, to thematize the appropriateness of a "logic of probability" for validation (in contrast to verification) of conflicting claims as to the nature of reality in the imaginativelyconstituted world of the self and the text.[69]

When students enter the writing process, then, we expect them to do so as selves, rather than as egos (using both of these terms in Ricoeur's sense). The enlightened position we hope to encourage is described by Ricoeur as one in which, when "arguing about the meaning of an action [or a text,] I put my wants and beliefs at a distance and submit then to a concrete dialectic of confrontation with opposite points of view."[70] That dialogue of selves within the public sphere established by text is critical thinking as a force for enlightenment.[71] 


\section{Notes}

[1] Richard Paul, "Teaching Critical Thinking in the 'Strong' Sense: A Focus on Self-Deception, World Views, and a Dialectical Mode of Analysis," Informal Logic Newsletter 4: 2-7 (May 1982). Hereafter, cited as "Paul."

[2] The most relevant texts would be: for Angus, Technique and Enlightenment: Limits of Instrumental Reason (Washington D.C.: Center for Advanced Research in Phenomenology and University Press of America, 1984). Hereafter, cited as "Angus." For Husserl, The Crisis of European Sciences and Transcendental Phenomenology, trans. D. Carr (Evanston: Northwestern University Press, 1970) and Formal and Transcendental Logic, trans. D. Cairns (The Hague: Nijhoff, 1969). For Critical Theory, Max Horkheimer and Theodor W. Adorno, Dialectic of Enlightenment, trans. J. Cumming (New York: Herder and Herder, 1972) and Max Horkheimer, "Traditional and Critical Theory," in Critical Theory, trans. $M$. O'Connell et. al. (New York: Herder and Herder, 1972).

[3] The most relevant text would be: Paul Ricoeur, Hermeneutics and the Human Sciences: Essays on Language, Action, and Interpretation, trans. J.B. Thompson (Cambridge: Cambridge University Press, 1981). Hereafter, cited as "Ricoeur." For a discussion of egocentricity as inevitable but transcendable, see my "Egocentricity: What it is and Why it matters," presented at the Fourth International Conference on Critical Thinking and Educational Reform, Sonoma State University, August 1986.

[4] Angus, 94 (my emphasis).

[5] Paul, 3.

[6] As he notes (in his footnote 24, p. 12), "while it is legitimate to attribute the term 'instrumental reason' to Horkheimer, it is by no means his favored one." The term is used quite generally in the Frankfurt School tradition; Angus's correlative term, "judgment," is equally common in the Kantian and Husserlian traditions.

[7] Angus, 17.

[8] Angus, 56, 67, 121, 135-137, 140-141. Although Angus's analysis denies the possibility of any such grounding, Husserl's places any such claim "under the epoche." That is, the possibility is not denied, but it is rigorously removed from consideration.

[9] Angus, 4; cf. 12, 48, 51, 85.

[10] This phrase is used throughout Angus's book to refer to the historical effect of "universalized instrumental reason."

[11] Paul, 3.

[12] Paul, 2.

[13] Angus, 19.

[14] These "translations" between Marxian and Husserlian vocabularies are accurate, I would argue; but that argument cannot be given here. I use them as if they were unproblematic, for heuristic purposes: i.e., to stress the convergence between some strands of neomarxist analysis (such as Critical Theory) and Husserlian phenomenological analysis. Also, I use them to reinforce the reciprocity of evidence Angus finds in Husserl's analysis of lived experience as the origin and telos of ideal structures (theoretical entities), and neomarxian (even, perhaps, Marx's) analysis of economic base and ideological superstructure.

[15] Angus, 56; cf. footnote 8.

[16] Angus, 33. 
[17] Angus, 20.

[18] Angus, 93.

[19] Angus, 126-127 (my emphasis).

[20] Angus, 125. This accessibility of objects as both presented in individual, immediate experience and represented in systems is a major difference between Husserl's analysis and those semiotic and hermeneutic traditions which hold that we have access only to objects as constituted by system. For these latter traditions, our reflection can only capture experience as already limited by systems (and so, informed by theory and history); it cannot also encounter immediately present facets of a pre-theoretical lifeworld.

[21] Angus, 142-143 (my emphasis).

[22] Paul, 3-4 (my emphasis).

[23] Paul, 5 (my emphasis).

[24] Paul, 5. In keeping with the persistently self-critical character stressed in the notion of judgment; I would note that the instructions (given to the students who are to analyze the "incompatible world views" represented in these films) are heavy with cultural assumptions. Paul characterizes the two positions as "a right-wing thinktank film alleging..." and a "World Council of Church's [sic] film in defense..." (Angus, 6).

[25] Paul, 4.

[26] Paul, 5.

[27] Angus, 143 (quoted in context in the quotation identified in footnote 21). In Husserlian terms, this step would be the "transcendental reduction"; i.e., the focus on "any subjectivity whatever" or on the. very possibility of reasoningrather than on any particular, individual reasoning process.

[28] Angus, 143.
[29] Paul, 7.

[30] Hannah Arendt, The Life of the Mind, Vol. 2 (New York: Harcourt, 1978), 257 (my emphasis). Quoted by Angus (page 107).

[31] Jerry Mander, Four Arguments For The Elimination of Television (New York: Quill, 1978, 200-201 (my emphasis). Hereafter cited as Mander.

[32] Mander, 310, 350.

[33] Mander, 204 (my emphasis).

[34] Arendt, 257; quoted in context at the start of Part Two.

[35] Angus, 105; see footnote 20 and accompanying text for "representation." The enclosed quotation is from Immanuel Kant, Critique of Judgment, trans. J.H. Barnard (New York: Collier Macmillian, 1974), 15. The suggestion arising even from this very brief treatment of the connection between the subject's use of imagination to transcend "ego" in a movement toward "self" as prerequisite for the practice of critical thinking/judgment - is that "pure reason" may be dependent upon "judgment." (That is: the First Critique may be grounded in the Third.) Obviously, this is a proposition requiring consideration in a very different essay, which must also consider the connections and discrepancies between Kant's use of "imagination" and the term as used by Angus, Arendt, Mander, Paul, and Ricoeur.

[36] Paul, 3.

[37] Paul, 4-5 (my emphasis).

[38] Paul, 6. Although the two films are the primary sources of information for these imaginative constructions, Paul notes that they are supplemented by a variety of sensory stimulation and include the reading of texts. Furthermore, 
Mander argues that film technology, although it makes use of some of the same surface techniques as television (e.g., highcontrast scenes and a predominance of close-ups) is not as restricted to them; nor does the film rely on the same neurophysiological techniques (e.g., projection of "non-existent" images).

[39] Mander, 209.

[40] Mander, 276 (my emphasis).

[41] Mander, 168 (my emphasis).

[42] Mander, 291.

[43] Mander, 198.

[44] Mander, 300.

[45] Mander, 254. He identifies the report as Television and Social Behavior, Vol. 4, "prepared by the National Institute of Mental Health for the Department of Health, Education, and Welfare."

[46] These phrases from Arendt are quoted in context at the start of this section.

[47] Paul, 3.

[48] Ricoeur, 292-293 (my emphasis). Ricoeur notes that he is using Nelson Goodman's term, "symbolic systems," interchangeably with "fiction."

[49] Ricoeur, 192-193 (author's emphasis).

[50] The terms in quotation marks are from Mander, 132-133, 197-198, 200-201, 300; all are quoted in context elsewhere in the text.

[51] Mander, 87.

[52] Mander, 336; cf. 202-203.

[53] Mander, 208; quoting Herbert Krugman.

[54] Ricoeur, 94 (my emphasis); cf., 188 and footnote 35.
[55] Ricoeur, 93 (my emphasis); cf., 142-143.

[56] Ricoeur, 192. My allusion is to St. Augustine's account of his conversion (Confessions, Books Eight and Nine). Translated into the vocabulary of this paper: after years of wandering in civilization as an ego, he encounters a text which instigates the replacement of ego with self and retires to the countryside to integrate this transformation. The public manifestation of this private enlightenment is a change of occupation: he resigns his rhetoric professorship and takes Holy Orders.

[57] Ricoeur, 92.

[58] Mander, 201; quoted in context at the start of Part Two.

[59] Ricoeur, 94.

[60] Ricoeur, 185.

[61] Ricoeur, 192; quoted in context at the start of Part Three.

[62] Ricoeur, 113-114 (author's emphasis).

[63] Ricoeur, 113.

[64] Ricoeur, 181.

[65] I follow E.D. Hirsch, Jr. in using "meaning" and "significance" in this way, to differentiate the world-of-the-text from the enlarged world-of-the-subject who appropriates that text. See, e.g., Validity in Interpretation (New Haven: Yale University Press, 1967), and The Aims of Interpretation (Chicago: The University of Chicago Press, 1976), 1-6.

[66] Ricoeur, 94. The dialectical nature of this process must be stressed. In Hegelian terms: the ego externalizes itself in an objective moment (the text) that originates beyond ego and resists ego's attempt to reduce the text to its own projection. Yet in being understood, 
sublation (die Authebung) occurs: self, as the unification of subject (reader) and object (text) comes into being.

This essential persistence of the text as a perennially available moment of objectivity is crucial to Ricoeur's text theory, and thus, to the conception of enlightenment I propose with that theory as basis. As a structural feature that insists upon the availability of objective meaning, it provides a sharp contrast to that variant of the "power of imagination" which I would call the "power of deconstruction," as originated by Jacques Derrida.

By discouraging passivity toward the text, deconstruction provides a force against the ingestion of any system that would limit an ego to instrumental reason, i.e., render it incapable of judging beyond established, "given," means-ends complexes. Thus, deconstruction seems to use the distanciation moment (or move) in Ricoeur's dialectic, perhaps even to the point of the disappearance of the subject(s) (the author and/or reader) as well as the object (the text) into an all-encompassing process: the technique called deconstruction.

However, insofar as deconstruction as a technique does reach that point, it is incapable of practicing the appropriation moment in $\mathrm{Ri}$ coeur's dialectic. For it has brought about the destruction of the text as an objective resource, i.e., as an omni-temporal meaning, potentially available for an infinitude of actualizations by subjects who read it. In other words, the ego, in explaining the text as a humanly-created process, had explained away the text as objective ideality. As a result, there is no non-egocentric world to appropriate in understanding as the new, imaginatively constructed locus for constituting a self. The ultimate result is then limitation to technique (the deconstructive process) and the reversal of enlightenment (by eliminating the conditions for the possibility of constituting self and world).

There is another way to look at the deconstructing process which also results in the frustration of Ricoeur's dialectic. This occurs if the process is understood as originating in the ego, rather than in the encounter with the text. Ricoeur's critique of the subjectivizing tendency which he finds beginning in Descartes and continuing into Gadamer then becomes relevant. (See Ricoeur, 190-192, 66-68.) The process begins and ends with ego; deprived of object (text) as the external moment to be encountered, self cannot emerge: there is no opportunity to "exchange the me, master of itself, for the self, disciple of the text." (Ricoeur, 113; cf. G.W.F. Hegel. The Phenomenology of Spirit, Section B.4.A.)

[67] Ricoeur, 191.

[68] The project, entitled "CACTIP: Composition, Analysis of Text, Critical Thinking Integrated Program," has been funded by the Division of Educational Programs, National Endowment for the Humanities, for implementation J une 1985 - May 1987.

[69] Ricoeur, 211-213; cf., 175. Ricoeur mentions his reliance upon Hirsch's theory of text here; see footnote 65 .

[70] Ricoeur, 214.

[71] This paper was presented at the Third International Conference on Critical Thinking and Educational Reform, Sonoma State University, July 1985. An earlier version was read at the APA Pacific Division meeting in San Francisco, March 1985. I would like to thank Harold Alderman for his thoughtful and detailed comments on that paper. Briefer versions of this paper 
(which present Section Two in a self-contained form) were read at the AILACT session, APA Eastern Division meeting in Washington, D.C., December 1985; Christopher Newport College Conference on Critical Thinking, April 1986; and the International Conference on Argumentation in Amsterdam, June 1986.

I would like to acknowledge an especially extensive debt to these colleagues, students, and teachers with whom I've discussed various parts of the paper in its several versions: Ian Angus, Ron Bloomquist, Dennis Danvers, Jacques Derrida, Ralph Johnson, Robert E. Longacre, Tom McCormick, Nancy McKenzie, Richard Paul, Susan Lynn Peterson, Kenneth L. Pike, Thomas E. Porter, Harry Reeder, and Paul Ricoeur.

Dr. Lenore Langsdorf, Department of Philosophy, The University of Texas at Arlington, P.O. Box 19527, Arlington, Texas 76019 . 